\title{
Breast carcinomas expressing basal markers have poor clinical outcome regardless of estrogen receptor status
}

\author{
BONG KYUNG SHIN ${ }^{1,3}$, YOUNGSEOK LEE ${ }^{1,3}$, JUNG BOK LEE ${ }^{4}$, \\ HAN KYEOM KIM ${ }^{1,3}$, JAE BOK LEE ${ }^{2}$, SU JIN CHO ${ }^{1,3}$ and AEREE KIM ${ }^{1,3}$ \\ Departments of ${ }^{1}$ Pathology, ${ }^{2}$ Surgery, Korea University Guro Hospital, ${ }^{3}$ Korea Lung Tissue Bank, \\ 80 Guro-dong, Guro-gu, Seoul 152-703; ${ }^{4}$ Institute of Human Gene Study, Korea University \\ Ansan Hospital, Gojan 1-dong, Danwon-gu, Ansan, Gyeonggi-Do 425-707, Korea
}

Received October 11, 2007; Accepted December 4, 2007

\begin{abstract}
To evaluate the clinical significance of gene expression-based classification and define the characteristic features of the new basal-like subtype, invasive breast carcinomas were divided into ER, HER2, basal-like and null subtypes by immunohistochemical analysis. A total of 401 invasive breast carcinomas were submitted to tissue microarray and stained with ER, HER2, EGFR, c-KIT and cytokeratin (CK) 5/6. The basal-like tumors, defined as positive for one or more basal markers but negative for both ER and HER2, comprised $18.5 \%$. They were larger $(\mathrm{p}=0.041)$, showed higher grade $(\mathrm{p}<0.001)$, and more frequently expressed $\mathrm{p} 53(\mathrm{p}=0.003)$. Expression of the basal marker itself showed negative prognostic effect, particularly in node-positive group. Even ER-positive patients had far shorter disease-free survival (DFS) when the tumor coexpressed one or more basal marker $(\mathrm{p}<0.001)$. Discrimination of basal-like subtype or tumors positive for basal markers may be clinically significant also in the treatment and prognosis of breast carcinomas.
\end{abstract}

\section{Introduction}

Invasive breast carcinoma is the most common cancer in women in the western world (1). The incidence of this tumor has markedly increased in Korea during the last decade comprising $13 \%$ of all cancers, and it was the second most common cancer among Korean women between 1999 and 2001 (2).

Breast cancer is a heterogeneous disease with an increasing number of recognizable biological markers. A considerable amount of useful prognostic information is available via careful histological examination and a limited number of immuno-

Correspondence to: Dr Aeree Kim, Department of Pathology, College of Medicine, Korea University, 80 Guro-dong, Guro-gu, Seoul 152-703, Korea

E-mail: ark@korea.ac.kr

Key words: basal, breast carcinoma, gene expression profile, immunohistochemistry histochemical and molecular tests. For example, HER-2/neu gene amplification has been recognized as a factor of poor prognosis since Slamon reported its correlation with overall and disease-free survival (3-5). HER-2/neu overexpression is also known as a predictor of responsiveness to anti-HER2 monoclonal antibodies, specific chemotherapeutic agents and anti-estrogenic treatment $(6,7)$. Estrogen receptor (ER) is an established prognostic marker in breast cancer. ER expression is related to histologic grade, favorable clinical outcome and responsiveness to endocrine therapy. Recently, the technique of gene microarray has enabled classification of human cancers according to gene expression patterns, helping classify invasive breast carcinomas into several subgroups: ER-positive tumors (luminal A and luminal B types) and ER-negative tumors (HER2+ER-, basal-like, and unclassified types) (8-14). Among these subtypes, basal-like breast carcinoma has been identified as a distinct group with different clinical outcomes $(12,14)$. The basal-like subtype usually expresses, on immunohistochemistry and/or gene microarray, CK5/6, CK14 and CK17 and more frequently coexpresses vimentin, EGFR, c-KIT and p53 rather than the luminal type $(15,18)$.

The classification of breast cancers according to gene expression patterns is promising for providing considerable diversity for management options and predicting responsiveness to various therapeutic agents. However, routine use of cDNA microarray to characterize an individual case of breast carcinoma is not practical because of the requirement for fresh or frozen tissue and the high cost of the test itself. Thus, a simple and practical method of classification with the same result and clinical validity as gene microarray is needed. Several studies have suggested the immunohistochemistry performed on formalin-fixed and paraffin-embedded tissue sections could also apply the cDNA microarray-based classification conveniently (15-21).

In this study, invasive breast carcinomas were classified into ER, HER2, basal-like, and null subtypes, derived from the gene expression profile study, using routine immunohistochemical studies on tissue microarray sections. In particularly, the basal-like subtype was closely evaluated for the clinicopathological characteristics and correlation with prognostic parameters. 


\section{Materials and methods}

Patients. Four hundred and twenty-nine women with invasive breast carcinoma between January 1992 and December 2004 were selected from the pathology files of Korea University Guro Hospital. All of them had undergone modified radical mastectomy, breast conserving operation, or excisional biopsy and had then received a diagnosis by histological examination. In 28 patients, the tissue cores obtained from the tumor sections contained an invasive cancer area $<10 \%$ of the whole combined core areas and were excluded from the final analysis. Information about metastasis, recurrence and patient's survival was obtained from medical records. This study was approved by the Institutional Review Board of Korea University Guro Hospital.

Tissue microarray. The recipient blocks were made of purified agar in a 3.8x2.2 cm-sized frame. Holes $2 \mathrm{~mm}$ in diameter were made by a biopsy punch (Kai Industries Co., Ltd., Seki, Japan), and the agar cores were discarded. The donor blocks were prepared after microscopic evaluation of the hematoxylinand eosin-stained slides. Representative cancer areas were obtained from the matching donor blocks and transplanted into the recipient blocks. Two cores from different tumor areas were selected in each tumor. Each core was separately put into a different block. The recipient blocks were framed in the mold used for the conventional paraffin blocks, and paraffin was then added to the frame.

Immunohistochemistry. Tissue microarray sections (4-5 $\mu \mathrm{m}$ thick) were used for immunohistochemical analysis. Briefly, after deparaffinization and rehydration the tissue sections were processed for antigen retrieval by pressure cooking or enzymatic digestion. Non-specific reactivity was blocked with $0.3 \% \mathrm{H}_{2} \mathrm{O}_{2}$ in a buffer. The sections were incubated with primary antibodies for $2 \mathrm{~h}$ at room temperature. The primary antibodies used are as follows: ER [mouse monoclonal (ID5); 1:50, Dako, Denmark], PR [mouse monoclonal (PgR636); 1:100, Dako], HER2 [mouse monoclonal (CB11); 1:100, NeoMarker Inc., Fremont, CA], p53 [mouse monoclonal (DO7); 1:100, Novocastra, Newcastle upon Tyne, UK], Ki67 [mouse monoclonal (MIB-1); 1:400, Dako], CK5/6 [mouse monoclonal (D5/16B4); 1:200, Dako], EGFR (PharmDx kit, Dako) and C-KIT (polyclonal; 1:250, Dako). After multiple washes with the buffer, the tissue sections were sequentially incubated for $30 \mathrm{~min}$ at room temperature with diluted biotinylated secondary antibody (1:500, Dako) and Vectastain Elite $\mathrm{ABC}$ reagent (Vector Laboratories, Inc., Burlingame, CA) diluted in phosphate-buffered saline (PBS). They were then examined after reaction with diaminobenzidine (Dako) and hematoxylin counterstain. Normal breast tissue was used as a positive control in each staining batch. The negative controls were obtained by omitting the primary antibodies.

Pathological examination and immunohistochemistry scoring. The histologic features and immunohistochemical profiles were reviewed by two pathologists. The grades of tumors were determined independently using the Nottingham histologic grades. The ER and PR stains were estimated according to the scoring system reported by Allred et al (22).
Briefly, a proportion score was assigned that represented the estimated proportion of positive tumor cells on the entire core as follows: 0 , none; $1,<1 / 100 ; 2,1 / 100-1 / 10 ; 3,1 / 10-1 / 3 ; 4$, $1 / 3-2 / 3$; and $5,>2 / 3$. An intensity score was assigned that estimated the average staining intensity of positive tumor cells as follows: negative, 0 ; weak, 1; intermediate, 2; and strong, 3 . The proportion score and intensity score were added to obtain a total score (ranging 0 and 2-8). A positive result was defined as the total score $\geq 3$. As for the HER2 and EGFR interpretation, only cancer cells with well-defined membrane stain were evaluated for the determination of the percentages of HER2 and EGFR immunoreactive cells. Both were evaluated according to the HercepTest method (23-25). Cores with over $10 \%$ of strong membrane staining were assigned score 3 . Cores with over $10 \%$ moderate staining were assigned score 2 . Cores with over $10 \%$ weak staining were assigned score 1. A positive result for HER2 was defined if the score was 3 while that for EGFR was defined if the score was 2 or 3 . The CK 5/6 and c-KIT were interpreted as positive with any weak or strong cytoplasmic and/or membranous staining.

The tumors were classified into four different subgroups, i.e., ER, HER2, basal-like and null types, according to the immunohistochemical expression profiles of ER, HER2, EGFR, c-KIT and CK5/6 (17): 1, HER2 type: all the HER2positive tumors; 2, ER type: all the ER-positive and HER2negative tumors; 3, Basal-like type: tumors positive for any of the three basal markers, i.e., EGFR, c-KIT and CK5/6, among the ER-negative and HER2-negative ones; and 4, Null type: tumors negative for all the five markers used in the classification.

Statistical analysis. Statistical analysis was performed using SPSS 12.0 for Windows (SPSS, USA) and SAS 9.1.3 for Windows (SAS, USA). A $\chi^{2}$ test or Fisher's exact test were used for determining the associations between the clinicopathological parameters and the immunohitochemical profiles of the breast cancers. Survival curves were calculated by the Kaplan-Meier method. The differences between survival rates were evaluated by the Peto and logrank test. P-values $<0.05$ were considered statistically significant.

\section{Results}

Clinicopathological characteristics. A total of 401 cases of invasive breast carcinomas with an age range of 23-82 were analyzed. Histologically, they consisted of 345 invasive ductal carcinoma NOS (82\%), 19 invasive lobular carcinomas $(4.7 \%), 8$ medullary carcinomas $(2.0 \%), 3$ metaplastic carcinomas $(0.7 \%), 11$ micropapillary carcinomas $(2.7 \%), 3$ mucinous carcinomas $(0.7 \%), 2$ tubular carcinomas $(0.5 \%), 2$ cribriform carcinomas $(0.5 \%), 1$ apocrine carcinomas and 7 mixed carcinomas $(1.7 \%)$. The tumor size was measurable in 397 cases. The largest dimension of the tumor was $\leq 2 \mathrm{~cm}$ in 166 cases $(41.8 \%),>2 \mathrm{~cm}$ but $<5 \mathrm{~cm}$ in $213(53.7 \%)$, and $>5 \mathrm{~cm}$ in $18(4.5 \%)$. Of the 385 cases with available data, 191 (49.6\%) were node-positive while 194 (50.4\%) were nodenegative. The tumors were stage I in 104 cases $(27.0 \%)$, stage II in $194(50.4 \%)$, and stage III in $87(22.6 \%)$. The 


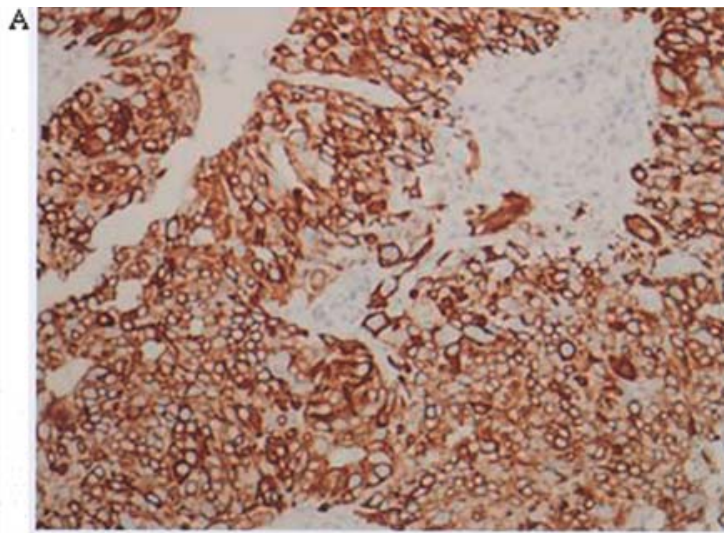

B
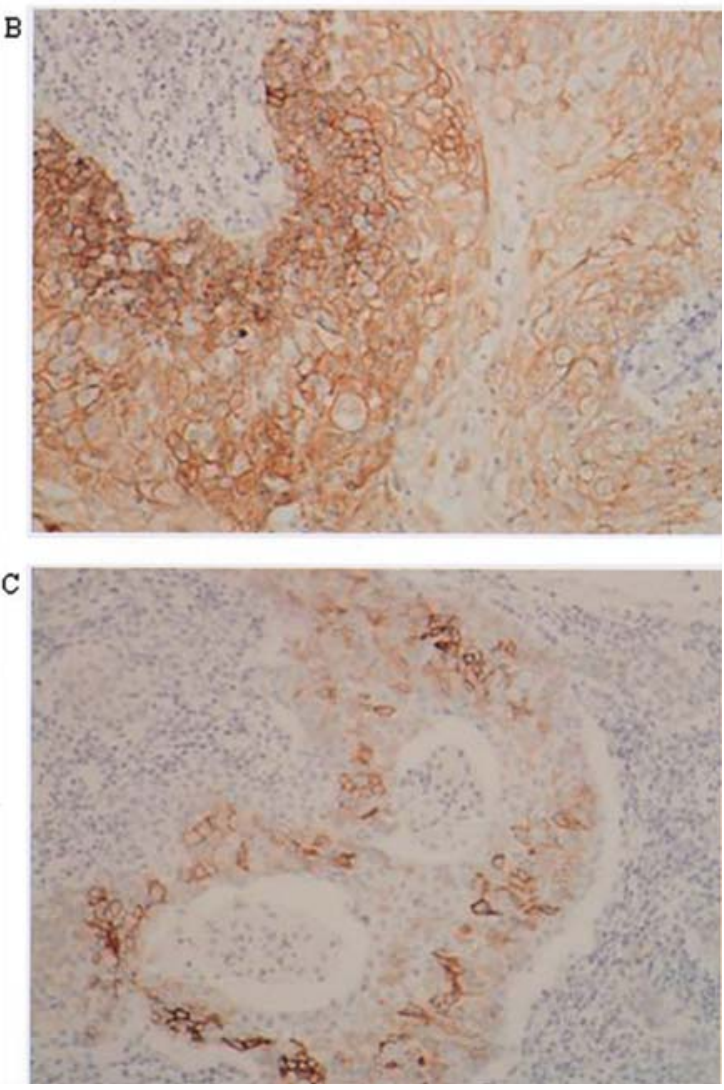

Figure 1. Immunohistochemical features of a basal-like breast carcinoma (metaplastic carcinoma with squamous differentiation). Most of the tumor cells express CK5/6 (A, immunoperoxidase, magnification x400). EGFR is expressed along the cytoplasmic membrane (B, immunoperoxidase, magnification $\mathrm{x} 400)$, and c-KIT is expressed in only a small percentage of tumor cells $(\mathrm{C}$, immunoperoxidase, magnification $\mathrm{x} 200)$.

Nottingham combined histologic grade was 1 in 85 cases $(21.2 \%), 2$ in $209(52.1 \%)$ and 3 in 107 cases $(26.7 \%)$.

Immunohistochemical characteristics. Immunohistochemical stains for ER, HER2, EGFR, c-KIT and CK5/6 were performed to classify the tumors into subtypes based on the gene expression patterns reported by Sorlie et al $(10,17)$. Out of 401 cases, 167 cases $(41.6 \%)$ expressed estrogen receptors and 65 cases $(16.2 \%)$ overexpressed HER2. As for the three basal markers, 60 cases $(15.0 \%)$ expressed EGFR while 57 cases $(14.2 \%)$ expressed CK5/6 and only 9 cases $(2.2 \%)$ c-KIT protein. Representative immunohistochemical results for basal markers are shown in Fig. 1.
Table I. Correlation between basal marker expression and other prognostic indicators of breast carcinomas.

\begin{tabular}{|c|c|c|c|c|}
\hline Variable & Total & $\begin{array}{c}\text { EGFR } \\
\text { expression } \\
(\%)\end{array}$ & $\begin{array}{c}\text { c-KIT } \\
\text { expression } \\
(\%)\end{array}$ & $\begin{array}{c}\text { CK5/6 } \\
\text { expression } \\
(\%)\end{array}$ \\
\hline \multicolumn{5}{|l|}{ Tumor size } \\
\hline$\leq 2 \mathrm{~cm}$ & 166 & $24(14.5)$ & $4(2.4)$ & $27(16.3)$ \\
\hline$\geq 2 \mathrm{~cm}$ & 135 & $36(15.3)$ & $5(2.1)$ & $30(12.8)$ \\
\hline P-value & & NS & NS & NS \\
\hline \multicolumn{5}{|l|}{ LN status } \\
\hline Positive & 191 & $30(15.7)$ & $1(0.5)$ & $32(12.0)$ \\
\hline Negative & 194 & $30(15.5)$ & $8(4.1)$ & $32(16.5)$ \\
\hline P-value & & NS & 0.037 & NS \\
\hline \multicolumn{5}{|l|}{ Grade } \\
\hline 1 & 85 & $5 \quad(5.9)$ & $0(0.0)$ & $2(2.4)$ \\
\hline 2 & 209 & $23(11.0)$ & $1(0.5)$ & $21(10.0)$ \\
\hline 3 & 107 & $32(29.9)$ & $8(7.5)$ & $34(31.8)$ \\
\hline $\mathrm{P}$-value & & $<0.001$ & $<0.001$ & $<0.001$ \\
\hline \multicolumn{5}{|l|}{ ER } \\
\hline Positive & 167 & $4 \quad(2.4)$ & $1(0.6)$ & $4 \quad(2.4)$ \\
\hline Negative & 234 & $56(23.9)$ & $8(3.4)$ & $53(22.6)$ \\
\hline P-value & & $<0.001$ & 0.087 & $<0.001$ \\
\hline \multicolumn{5}{|l|}{ PR } \\
\hline Positive & 132 & $2(1.5)$ & $1(0.8)$ & $4 \quad(3.0)$ \\
\hline Negative & 267 & $58(21.7)$ & $8(3.0)$ & 53 (19.9) \\
\hline P-value & & $<0.001$ & NS & $<0.001$ \\
\hline \multicolumn{5}{|l|}{ HER2 } \\
\hline Positive & 65 & $8(12.3)$ & $\begin{array}{ll}0 & (0)\end{array}$ & $5(15.5)$ \\
\hline Negative & 336 & $52(15.5)$ & $9(2.7)$ & $52(7.7)$ \\
\hline P-value & & NS & NS & NS \\
\hline \multicolumn{5}{|l|}{ p53 } \\
\hline Positive & 146 & 29 (19.9) & $4(2.7)$ & $24(16.4)$ \\
\hline Negative & 211 & $25(11.8)$ & $4(1.9)$ & $28(13.3)$ \\
\hline P-value & & 0.038 & NS & NS \\
\hline \multicolumn{5}{|l|}{ Ki67 index } \\
\hline$\geq 20 \%$ & 80 & $13(16.3)$ & $3(3.8)$ & $18(22.5)$ \\
\hline$\leq 20 \%$ & 308 & 45 (14.6) & $5(1.6)$ & $37(12.0)$ \\
\hline P-value & & NS & NS & 0.017 \\
\hline
\end{tabular}

LN, lymph node.

Immunohistochemical stains for PR, p53 and Ki67 were also performed as possible prognostic markers. The PR was interpretable in 399 cases with $33.1 \%$ (132 cases) positivity. The p53 was interpretable in 357 and positive in 146 cases $(30.9 \%)$ while the Ki-67 proliferation index was measurable in 388 cases and was over $20 \%$ in $80(20.6 \%)$.

Basal markers were associated with poor prognostic factors. Table I displays the expression rate of each basal marker in 
Table II. Correlation between histological and gene expression pattern-based subtypes of breast carcinomas.

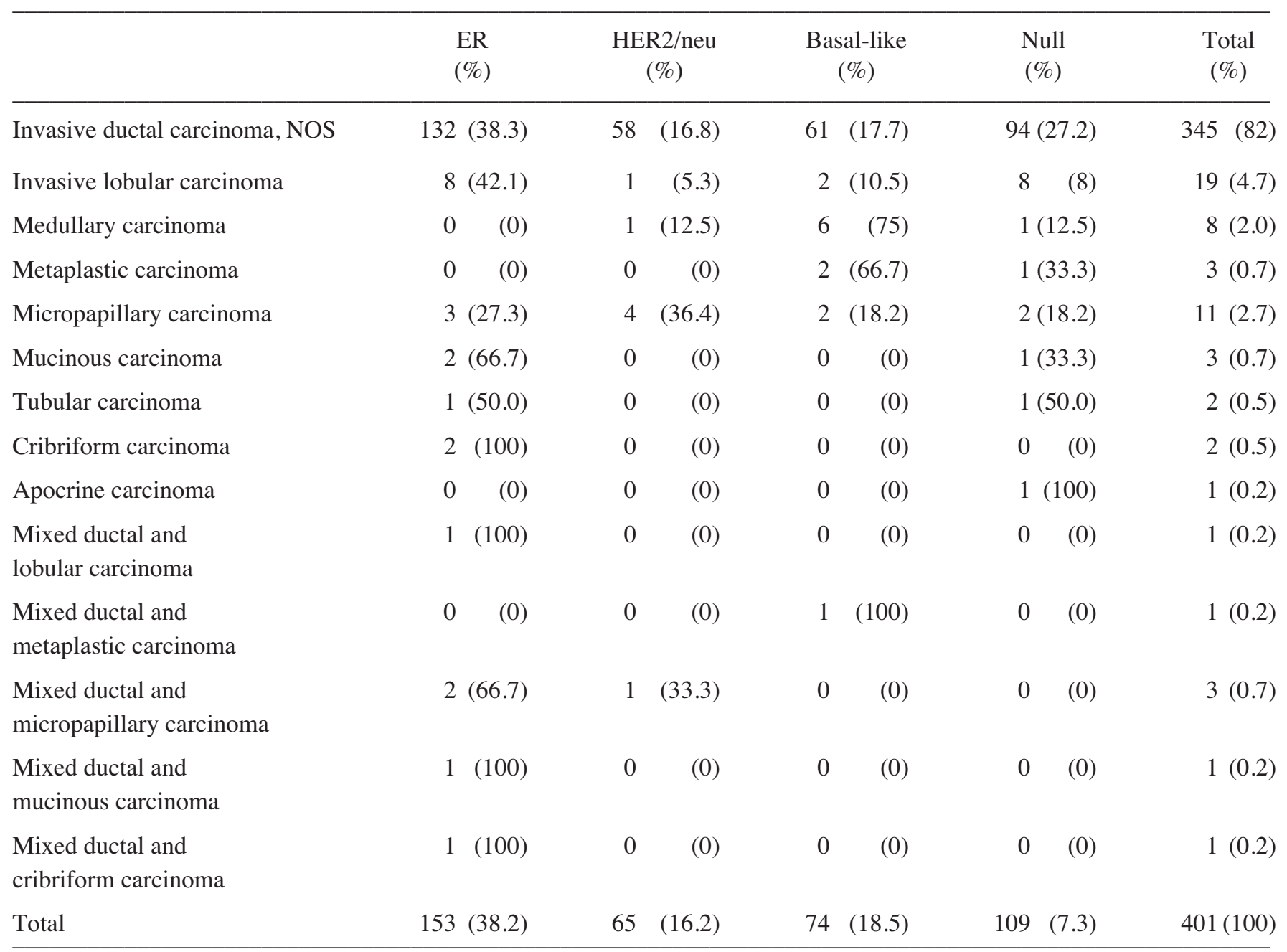

relation to other known prognostic indicators including ER and HER2 overexpression. The basal markers did not show any correlation with tumor size or lymph node status. However, the tumor grade positively correlated with each of the basal markers $(\mathrm{p}<0.001)$. While the EGFR and CK5/6 expression inversely correlated with ER and PR expression $(\mathrm{p}<0.001)$, no basal marker showed any relation to HER2/neu overexpression. The EGFR expression also correlated with p53 $(\mathrm{p}=0.038)$.

Breast carcinomas with medullary or metaplastic features and high grade ductal invasive carcinomas tend to be of the basal-like subtype. Table II displays the histologic subtypes of the breast carcinomas in relation to the gene expression pattern subtypes. Among the various histologic subtypes, medullary carcinoma and metaplastic carcinoma were composed of a higher proportion of basal-like tumors than the other types. Six out of eight medullary carcinomas (75.0\%), two of three metaplastic carcinomas, and one mixed ductal and metaplastic carcinoma with squamous differentiation belonged to the basal-like subtype (Fig. 2). Among the invasive ductal carcinomas, the basal-like subtype correlated with the histological grade. Sixty-one invasive ductal carcinoma NOS cases were of the basal-like subtype, of which 35 cases $(37.7 \%)$ were of grade 3, $23(37.7 \%)$ were of grade 2 , and $3(4.9 \%)$ were of grade 1 .

The histological characteristics of the basal-like breast carcinomas are summarized in Table III. In general, basallike tumors were more likely to be of a higher grade than the other subtypes $(\mathrm{p}<0.001)$ with poor tubule formation, solid architecture with extensive geographic tumor necrosis, pleomorphic nuclei and high mitotic count (Fig. 2).

The basal-like subtype correlated with factors of poor prognosis. In this study, the breast carcinomas were classified into four distinct subtypes, i.e., ER, HER2, basal-like and null, according to the immunohistochemical profile reflecting the gene expression pattern. Of the 401 tumors, 153 (38.2\%) were ER type, 65 (16.2\%) were HER2 type, 74 (18.5\%) were basal-like type and 109 (7.3\%) were null type. To clarify the prognostic impact of the subtypes based on the gene expression pattern analysis was performed to determine whether those subtypes were associated with previously known prognostic indicators such as tumor size, grade, hormone receptor status, p53 expression and Ki-67 proliferation index (Table IV). The basal-like and null subtype tumors were more likely to be $>2 \mathrm{~cm}(\mathrm{p}=0.041)$. The basallike tumors were also more likely to be PR-negative $(\mathrm{p}<0.001)$ 


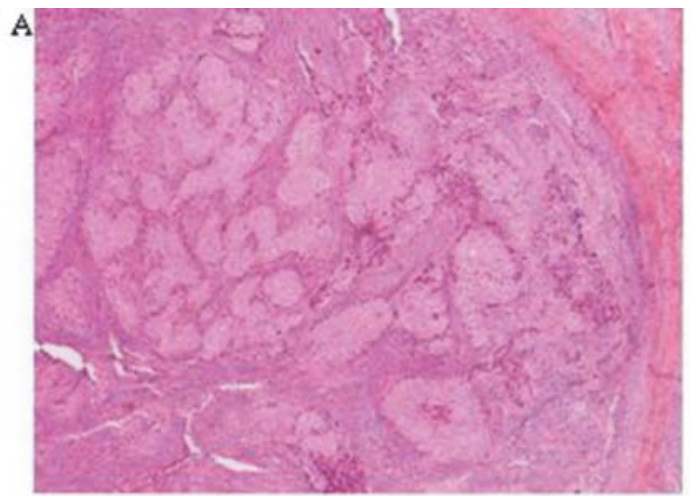

C

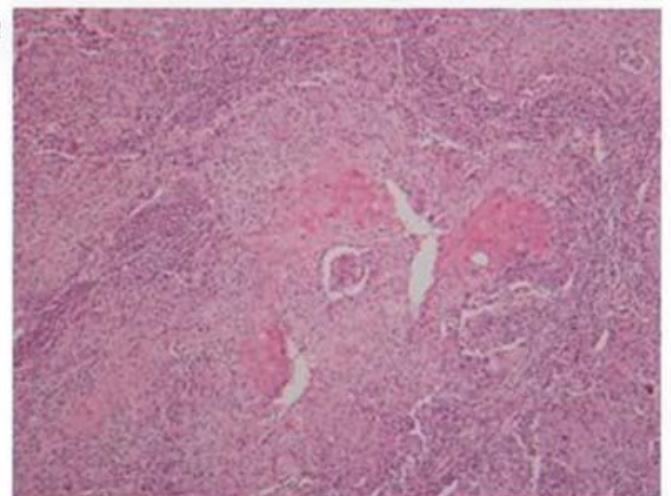

E

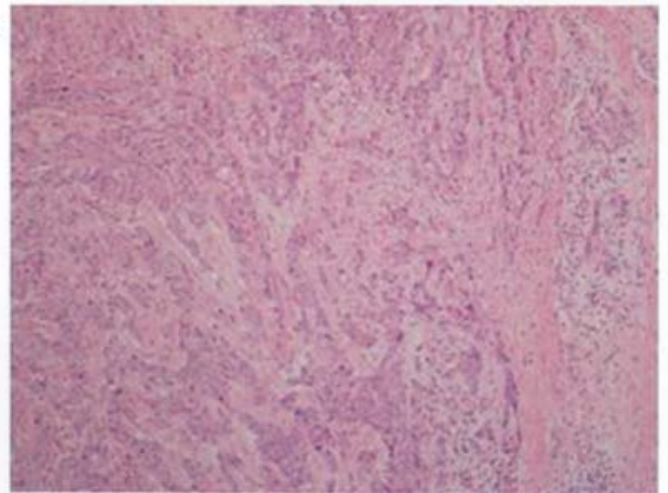

B

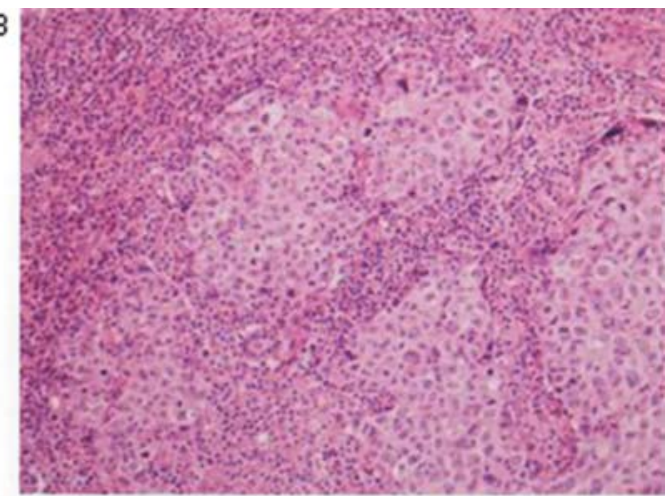

D

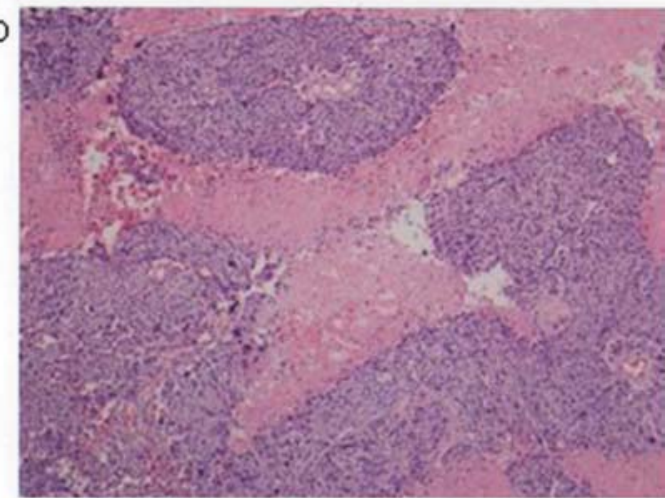

F

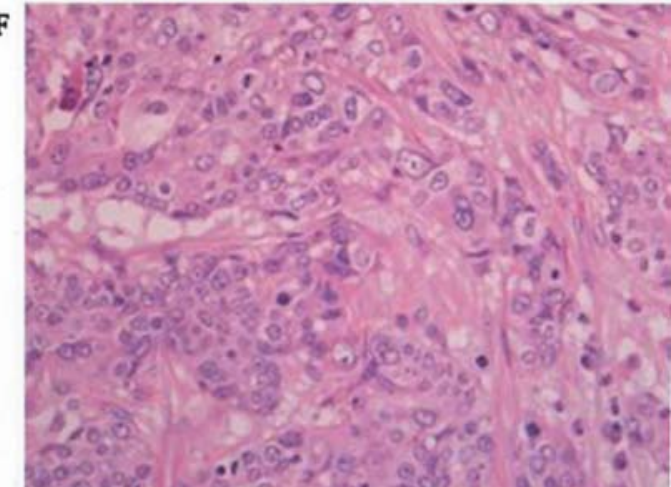

Figure 2. Histological features of basal-like breast carcinoma. The medullary carcinoma with basal-like immunohistochemical characteristics shows complete circumscription with a pushing margin [(A) H\&E, magnification x40] and syncytial growth of large pleomorphic cells with lymphocytic infiltration [(B) $\mathrm{H} \& \mathrm{E}$, magnification $\mathrm{x} 400]$. Another basal-like carcinoma demonstrates a metaplastic histology and squamous differentiation [(C) H\&E, magnification x100]. The invasive ductal carcinomas with basal-like features characteristically show a solid growth pattern with geographic necrosis [(D) H\&E, magnification $\mathrm{x} 40$ ], high histological grade with pleomorphic nuclei and frequent mitoses [(E) H\&E, magnification x100; (F) H\&E, magnification x400].

in contrast to the ER type tumors, higher in histologic grade $(\mathrm{p}<0.001)$, and $\mathrm{p} 53$-positive $(\mathrm{p}=0.003)$.

Expression of a basal marker is associated with a poor clinical outcome in node-positive breast carcinomas. In node-negative breast carcinomas, the Kaplan-Meier survival analysis showed the 5-year disease-free survival rates respectively to be $91.3,75.0,88.5$ and $84.4 \%$ for the ER, HER2, basal-like and null subtypes without statistically significant difference (data not shown). In the node-positive group, however, the 5-year disease-free survival rates of basal-like and null subtypes were significantly shorter than those of ER and HER2 types ( $\mathrm{p}=0.0372$ by the Peto test) (Fig. 3 ). In four patients with ER type tumors expressing one or more of the basal markers, the 5-year disease-free survival rate was far shorter than both of ER-positive/basal-negative and ERnegative groups $(\mathrm{p}<0.001$ by the log-rank test), suggesting that the expression of the basal marker is associated with shorter survival regardless of the hormone receptor status of the tumor (Fig. 4).

\section{Discussion}

Breast cancer is not homogeneous even within a single histological subtype. Invasive ductal carcinoma not otherwise specified (NOS) comprises about $79 \%$ of all invasive breast cancer cases. However, the biological and clinical characteristics of individual tumors, which may influence the patient's clinical course and outcome, are variable. For a better assessment and prediction of the cancer behaviors, a new classification scheme that clearly represents the characteristics may be required.

Analysis of gene expression patterns has classified various tumors into distinct clinically and biologically significant 
Table III. Histological characteristics of the basal-like breast carcinomas of various histologic subtypes.

\begin{tabular}{|c|c|c|c|c|c|c|c|}
\hline & \multicolumn{6}{|c|}{ Histologic subtype } & \multirow[b]{2}{*}{ Tota } \\
\hline & $\begin{array}{c}\text { IDC } \\
\mathrm{N}=61\end{array}$ & $\begin{array}{c}\text { IDC+metaplastic } \\
\mathrm{N}=1\end{array}$ & $\begin{array}{l}\mathrm{MC} \\
\mathrm{N}=6\end{array}$ & $\begin{array}{c}\text { Metaplastic } \\
\qquad \mathrm{N}=2\end{array}$ & $\begin{array}{l}\text { ILC } \\
\mathrm{N}=2\end{array}$ & $\begin{array}{l}\text { Micropapillary } \\
\quad \mathrm{N}=2\end{array}$ & \\
\hline \multicolumn{8}{|l|}{ Tubules } \\
\hline Poor & 50 & 1 & 5 & 2 & 2 & 2 & 62 \\
\hline Moderate & 11 & 0 & 1 & 0 & 0 & 0 & 12 \\
\hline Well & 0 & 0 & 0 & 0 & 0 & 0 & 0 \\
\hline \multicolumn{8}{|l|}{ Nuclear grade } \\
\hline High & 51 & 1 & 6 & 1 & 2 & 2 & 63 \\
\hline Intermediate & 10 & 0 & 0 & 1 & 0 & 0 & 11 \\
\hline Low & 0 & 0 & 0 & 0 & 0 & 0 & 0 \\
\hline \multicolumn{8}{|l|}{ Solid pattern } \\
\hline Present & 33 & 0 & 6 & 0 & 0 & 0 & 39 \\
\hline Absent & 28 & 1 & 0 & 2 & 2 & 2 & 35 \\
\hline \multicolumn{8}{|l|}{ Necrosis } \\
\hline Present & 33 & 1 & 3 & 0 & 0 & 1 & 38 \\
\hline Absent & 28 & 0 & 3 & 2 & 2 & 1 & 36 \\
\hline \multicolumn{8}{|l|}{ Mitosis } \\
\hline$-6 / 10 \mathrm{HPF}$ & 8 & 0 & 0 & 0 & 1 & 0 & 9 \\
\hline 7-16/10HPF & 5 & 1 & 0 & 1 & 1 & 1 & 9 \\
\hline 17-/10HPF & 48 & 0 & 6 & 1 & 0 & 1 & 56 \\
\hline \multicolumn{8}{|c|}{ Squamoid pattern } \\
\hline Present & 0 & 1 & 0 & 0 & 0 & 0 & 1 \\
\hline Absent & 61 & 0 & 6 & 2 & 2 & 2 & 73 \\
\hline \multicolumn{8}{|l|}{ Inflammation } \\
\hline Present & 29 & 0 & 4 & 0 & 0 & 1 & 34 \\
\hline Absent & 32 & 1 & 2 & 2 & 2 & 1 & 40 \\
\hline \multicolumn{8}{|l|}{ Desmoplasia } \\
\hline Present & 31 & 1 & 0 & 1 & 2 & 1 & 36 \\
\hline Absent & 30 & 0 & 6 & 1 & 0 & 1 & 38 \\
\hline \multicolumn{8}{|l|}{ Border } \\
\hline Pushing & 18 & 0 & 5 & 1 & 0 & 1 & 25 \\
\hline Infiltrative & 43 & 1 & 1 & 1 & 2 & 1 & 9 \\
\hline
\end{tabular}

IDC, invasive ductal carcinoma; MC, medullary carcinoma; ILC, invasive lobular carcinoma.

subgroups (26-29). Breast cancer has also been proved to be heterogeneous and is classified into several distinct groups based on the results of gene microarray analysis $(10,13,27,30-32)$. Among the subgroups of breast cancer, the basal-like subtype has been newly defined, primarily based on the gene expression profile and was then proven to be associated with a poor prognosis by follow-up studies $(10,11,14,19,21)$. According to the accumulated data from previous studies, the basal-like subtype tends to be a high grade, solid tumor with a lack of tubule formation, high mitotic count and necrosis (16). The result of this study also demonstrated the basal-like breast carcinomas as generally higher in histological grade, solid in growth pattern, and frequently correlated with medullary features or squamous differentiation. However, medullary or metaplastic carcinoma was not the most common histological type of basal-like tumors. The invasive ductal carcinoma NOS was the majority (61 out of 71 cases) of the basal-like breast carcinoma cases in the result of this study and composed a greater part of the previously-mentioned solid tumor with no tubule formation, higher nuclear grade, frequent mitoses and extensive geographic necrosis.

The basal-like subtype of breast carcinoma has been characterized by the gene expression of CK5, CK14, CK17, 
Table IV. Clinicopathologic characteristics of gene expression-based subtypes of breast carcinomas.

\begin{tabular}{|c|c|c|c|c|c|c|}
\hline \multirow[b]{2}{*}{ Variable } & \multirow[b]{2}{*}{ No. $(\%)$} & \multicolumn{4}{|c|}{ Subtypes } & \multirow[b]{2}{*}{ P-value } \\
\hline & & $\begin{array}{c}\mathrm{ER}(\%) \\
153(38.2)\end{array}$ & $\begin{array}{l}\text { HER2/neu (\%) } \\
65(16.2)\end{array}$ & $\begin{array}{c}\text { Basal-like (\%) } \\
74(18.5)\end{array}$ & $\begin{array}{l}\text { Null (\%) } \\
109(7.3)\end{array}$ & \\
\hline \multicolumn{7}{|l|}{ Tumor size } \\
\hline$\leq 2 \mathrm{~cm}$ & $166(41.4)$ & $74(48.4)$ & $18(27.7)$ & 31 (41.9) & $43(39.4)$ & 0.041 \\
\hline$>2 \mathrm{~cm}$ & 235 (58.6) & $79(51.6)$ & $47(72.3)$ & $43(58.1)$ & $66(60.6)$ & \\
\hline \multicolumn{7}{|l|}{ LN status } \\
\hline Positive & 191 (49.6) & $73(50.3)$ & $34(53.1)$ & 30 (41.7) & $54(51.9)$ & 0.496 \\
\hline Negative & $194(50.4)$ & $72(49.7)$ & $30(46.9)$ & $42(58.3)$ & $50(48.1)$ & \\
\hline \multicolumn{7}{|l|}{ Grade } \\
\hline 1 & $85(21.2)$ & $54(35.3)$ & $9(13.8)$ & $4 \quad(5.4)$ & $18(16.5)$ & $<0.001$ \\
\hline 2 & $209(52.1)$ & $82(53.6)$ & $35(53.8)$ & $27(36.5)$ & $65(59.6)$ & \\
\hline 3 & 107 (26.7) & $17(11.1)$ & $21(32.3)$ & $43(58.1)$ & $26(23.9)$ & \\
\hline \multicolumn{7}{|l|}{ PR } \\
\hline Positive & $132(33.1)$ & 88 (57.9) & $12(18.8)$ & $3 \quad(4.1)$ & $29(26.6)$ & $<0.001$ \\
\hline Negative & 267 (66.9) & $64(42.1)$ & $52(81.3)$ & $71(95.9)$ & $80(73.4)$ & \\
\hline \multicolumn{7}{|l|}{ p53 } \\
\hline Positive & $146(40.9)$ & $39(29.1)$ & $31(52.5)$ & $35(50.7)$ & $41(43.2)$ & 0.003 \\
\hline Negative & $211(59.1)$ & $95(70.9)$ & $28(47.5)$ & $34(49.3)$ & $54(56.8)$ & \\
\hline \multicolumn{7}{|l|}{ Ki67 index } \\
\hline$\geq 20 \%$ & 80 (20.6) & $16(10.8)$ & 19 (30.6) & $21(29.2)$ & $24(22.6)$ & 0.002 \\
\hline$<20 \%$ & 308 (79.4) & $132(89.2)$ & $43(69.4)$ & $51(70.8)$ & $82(77.4)$ & \\
\hline
\end{tabular}

LN, lymph node.

c-KIT and EGFR, which are now generally considered as representative basal markers. Although the molecular techniques have remarkably advanced and are expected to play an important role in both clinical diagnosis and basic research, they have not arrived in routine clinical practices yet. Before gene microarray analysis was introduced, the ER or HER2 expression in breast cancer was routinely evaluated immunohistochemically as a predictive or prognostic marker (22,33). Since the description of the basal-like subtype of breast cancer based on the gene expression profile, it has been expected that recognition of this subtype would be important in clinical practice because of the association with poor prognosis and the potential for new target therapies. Many researchers have attempted the practical clinical application of the classification by an immunohistochemical approach in diagnostic pathology (14-20). In one study, the known basal cytokeratins CK5 and CK14 were coexpressed in most, though not all, of the basal-like carcinomas (34). CK8/18, although considered a luminal marker, was not helpful in differentiating luminal or ER subtypes from the basal-like subtype because the majority of breast cancers expressed CK8/18 regardless of their subtypes (34). The basal cells in the ductal epithelium express CK17 and CK5/6 in normal breast tissue (21). It is known that EGFR, an independent prognostic factor for breast cancer and a target for several drugs and therapeutic antibodies, is also frequently expressed in basal-like subtype cancers (16,35-37). EGFR was expressed in $15 \%$ of our cases and correlated with the expression of CK5/6. Although the gene expression analysis did not recognize it as a basal-subtype specific marker, EGFR seems also to be closely related with basal-like breast carcinoma. The expression rate of c-KIT, another basal marker, has been variously reported between 2.6 and $82 \%$ in invasive breast carcinomas $(36,38,39)$. This study revealed that c-KIT was strongly expressed in $2.2 \%$ and c-KIT expression was correlated with CK5/6 expression. Whether c-KIT and EGFR are valuable as immunohistochemical markers for the basal-like subtype of breast carcinoma remains to be confirmed, however, those variable expression patterns of different basal markers suggested the basal-like breast carcinoma could also be a heterogeneous group.

Nielsen et al reported that $22 \%$ of breast carcinomas belonged to the null subtype (17). In this study, $7.3 \%$ of enrolled cases were included in the null subtype without expressing any of the five markers. It is possible that the tissue cores that were selected for tissue microarray were not truly representative of the case because of the heterogeneity within one tumor mass or that some of the null tumors should really 


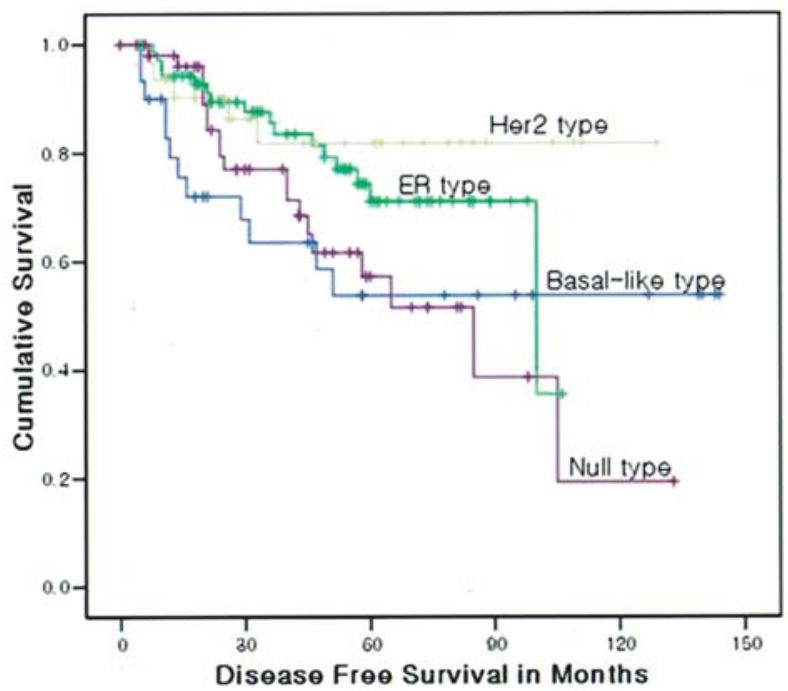

Figure 3. Kaplan-Meier disease-free survival analysis of gene expressionbased subtypes of breast carcinoma. The basal-like and null type carcinomas showed distinctively shorter DFS in the node-positive patient group $(\mathrm{p}=0.0372)$.

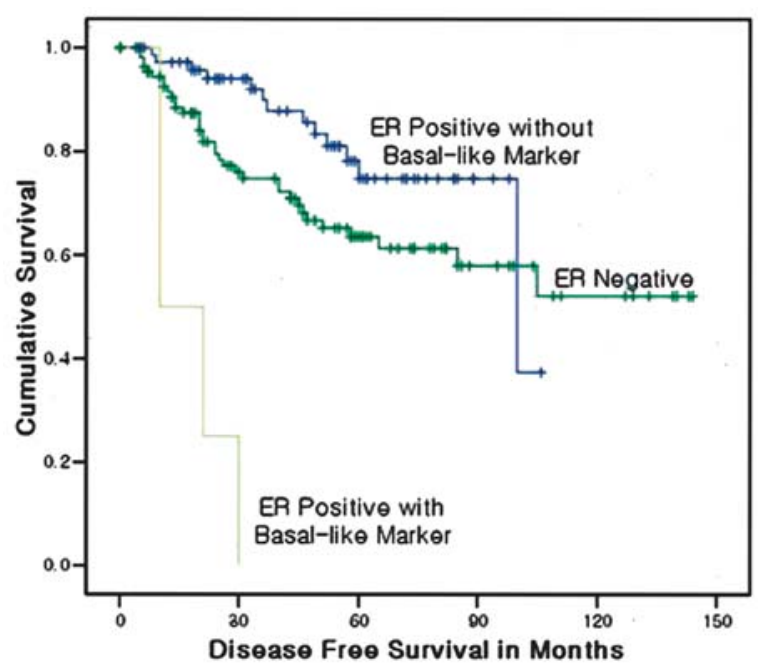

Figure 4. In the node positive group, tumors expressing more than one of the basal markers revealed a far shorter DFS than those expressing none, irrespective of the hormonal receptor status $(\mathrm{p}=0.0016)$.

be grouped as other types or the basal-like subtype if other markers for tumor classification had been included as in the study of Laakso et al, in which an antibody cocktail CK5/ CK14/p63 for basal-like breast carcinoma was used $(34,40)$. Correct identification of the basal-like subtype by immunohistochemistry may still need further trials regarding adequate selection of basal markers.

The basal-like subtype of breast carcinoma has been considered to be correlated with factors of poor prognosis such as a large tumor size, a high histological grade, a lack of hormone receptors ER and/or PR, and p53 overexpression (41). In this study, patients with basal-like breast cancer showed shorter disease-free survival than those with ER or HER2 subtypes. Furthermore, the expression of basal marker seemed itself to have a negative effect on prognosis, partially supported by the observation that in patients with metastatic lymph nodes the disease-free survival of the basal markerpositive cases was shorter than that of negative cases irrespective of their ER status. We hypothesized that the expression of basal markers could be associated with a tolerance against the selective estrogen receptor modulators.

In summary, this study confirmed that the basal-like breast carcinomas were correlated with other well-known factors of poor prognosis such as tumor size, grade, hormonal receptor status and p53 expression. Furthermore, it was observed that even in tumors expressing ER the presence of one or more basal markers had a negative prognostic effect particularly within the node-positive group. Conclusively the determination of the basal-like subtype or the expression of basal markers may be an important pathological examination to properly guide the management of breast cancer patients. The pathological parameters, immunohistochemical markers and techniques to define the basal-like subtype of breast carcinoma should be further clarified.

\section{Acknowledgements}

This study was supported by a Korea University Grant and Special Research Materials Banks grant from the Ministry of Science and Technology/Korea Science and Engineering Foundation (KOSEF, R21-2002-000-00015-0). We thank Iehwan Bae for his help with the immunohistochemical staining in this study. This study complied with the current laws of Korea.

\section{References}

1. Parkin DM, Bray F, Ferlay J and Pisani P: Estimating the world cancer burden: Globocan 2000. Int J Cancer 94: 153-156, 2001.

2. Society TKBC: Clinical characteristics of Korean breast cancer patients in 1998. J Korean Med Sci 15: 569-579, 2000.

3. Quenel N, Wafflart J, Bonichon F, et al: The prognostic value of c-erbB2 in primary breast carcinomas: a study on 942 cases. Breast Cancer Res Treat 35: 283-291, 1995.

4. Slamon DJ, Clark GM, Wong SG, Levin WJ, Ullrich A and McGuire WL: Human breast cancer: correlation of relapse and survival with amplification of the HER-2/neu oncogene. Science 235: 177-182, 1987

5. Thor AD, Schwartz LH, Koerner FC, et al: Analysis of c-erbB-2 expression in breast carcinomas with clinical follow-up. Cancer Res 49: 7147-7152, 1989

6. Pegram MD, Pauletti G and Slamon DJ: HER-2/neu as a predictive marker of response to breast cancer therapy. Breast Cancer Res Treat 52: 65-77, 1998.

7. Vogel CL, Cobleigh MA, Tripathy D, et al: First-line Herceptin monotherapy in metastatic breast cancer. Oncology 61 (Suppl. 2): S37-S42, 2001.

8. Liu ET and Sotiriou C: Defining the galaxy of gene expression in breast cancer. Breast Cancer Res 4: 141-144, 2002.

9. Perou CM, Sorlie T, Eisen MB, et al: Molecular portraits of human breast tumours. Nature 406: 747-752, 2000.

10. Sorlie T, Perou CM, Tibshirani R, et al: Gene expression patterns of breast carcinomas distinguish tumor subclasses with clinical implications. Proc Natl Acad Sci USA 98: 1086910874, 2001

11. Sorlie T, Tibshirani R, Parker J, et al: Repeated observation of breast tumor subtypes in independent gene expression data sets. Proc Natl Acad Sci USA 100: 8418-8423, 2003.

12. Sotiriou C, Neo SY, McShane LM, et al: Breast cancer classification and prognosis based on gene expression profiles from a population-based study. Proc Natl Acad Sci USA 100: 10393-10398, 2003.

13. Van't Veer LJ, Dai H, van de Vijver MJ, et al: Gene expression profiling predicts clinical outcome of breast cancer. Nature 415: 530-536, 2002. 
14. Van de Vijver MJ, He YD, van't Veer LJ, et al: A geneexpression signature as a predictor of survival in breast cancer. N Engl J Med 347: 1999-2009, 2002.

15. Callagy G, Cattaneo E, Daigo Y, et al: Molecular classification of breast carcinomas using tissue microarrays. Diagn Mol Pathol 12: 27-34, 2003.

16. Livasy CA, Karaca G, Nanda R, et al: Phenotypic evaluation of the basal-like subtype of invasive breast carcinoma. Mod Pathol 19: 264-271, 2006.

17. Nielsen TO, Hsu FD, Jensen K, et al: Immunohistochemical and clinical characterization of the basal-like subtype of invasive breast carcinoma. Clin Cancer Res 10: 5367-5374, 2004.

18. Tsuda H, Morita D, Kimura M, et al: Correlation of KIT and EGFR overexpression with invasive ductal breast carcinoma of the solid-tubular subtype, nuclear grade 3 , and mesenchymal or myoepithelial differentiation. Cancer Sci 96: 48-53, 2005.

19. Abd El-Rehim DM, Pinder SE, Paish CE, et al: Expression of luminal and basal cytokeratins in human breast carcinoma. J Pathol 203: 661-671, 2004.

20. Carey LA, Perou CM, Livasy CA, et al: Race, breast cancer subtypes, and survival in the Carolina Breast Cancer Study. JAMA 295: 2492-2502, 2006.

21. Van de Rijn M, Perou CM, Tibshirani R, et al: Expression of cytokeratins 17 and 5 identifies a group of breast carcinomas with poor clinical outcome. Am J Pathol 161: 1991-1996, 2002.

22. Allred DC, Harvey JM, Berardo M and Clark GM: Prognostic and predictive factors in breast cancer by immunohistochemical analysis. Mod Pathol 11: 155-168, 1998.

23. Jacobs TW, Gown AM, Yaziji H, Barnes MJ and Schnitt SJ: HER-2/neu protein expression in breast cancer evaluated by immunohistochemistry. A study of interlaboratory agreement. Am J Clin Pathol 113: 251-258, 2000.

24. Jacobs TW, Gown AM, Yaziji H, Barnes MJ and Schnitt SJ: Comparison of fluorescence in situ hybridization and immunohistochemistry for the evaluation of HER-2/neu in breast cancer. J Clin Oncol 17: 1974-1982, 1999.

25. Jacobs TW, Gown AM, Yaziji H, Barnes MJ and Schnitt SJ: Specificity of HercepTest in determining HER-2/neu status of breast cancers using the United States Food and Drug Administration-approved scoring system. J Clin Oncol 17: 1983-1987, 1999.

26. Alizadeh AA, Eisen MB, Davis RE, et al: Distinct types of diffuse large B-cell lymphoma identified by gene expression profiling. Nature 403: 503-511, 2000.

27. Golub TR, Slonim DK, Tamayo P, et al: Molecular classification of cancer: class discovery and class prediction by gene expression monitoring. Science 286: 531-537, 1999.
28. Hedenfalk I, Duggan D, Chen Y, et al: Gene-expression profiles in hereditary breast cancer. N Engl J Med 344: 539-548, 2001.

29. Perreard L, Fan C, Quackenbush JF, et al: Classification and risk stratification of invasive breast carcinomas using a realtime quantitative RT-PCR assay. Breast Cancer Res 8: R23, 2006.

30. Gruvberger S, Ringner M, Chen Y, et al: Estrogen receptor status in breast cancer is associated with remarkably distinct gene expression patterns. Cancer Res 61: 5979-5984, 2001.

31. Perou CM, Jeffrey SS, van de Rijn M, et al: Distinctive gene expression patterns in human mammary epithelial cells and breast cancers. Proc Natl Acad Sci USA 96: 9212-9217, 1999.

32. West M, Blanchette C, Dressman H, et al: Predicting the clinical status of human breast cancer by using gene expression profiles. Proc Natl Acad Sci USA 98: 11462-11467, 2001.

33. Birner P, Oberhuber G, Stani J, et al: Evaluation of the United States Food and Drug Administration-approved scoring and test system of HER-2 protein expression in breast cancer. Clin Cancer Res 7: 1669-1675, 2001.

34. Laakso M, Tanner M, Nilsson J, et al: Basoluminal carcinoma: a new biologically and prognostically distinct entity between basal and luminal breast cancer. Clin Cancer Res 12: 4185-4191, 2006.

35. Baselga $\mathrm{J}$ and Albanell $\mathrm{J}$ : Targeting epidermal growth factor receptor in lung cancer. Curr Oncol Rep 4: 317-324, 2002.

36. Tsutsui S, Yasuda K, Suzuki K, et al: A loss of c-kit expression is associated with an advanced stage and poor prognosis in breast cancer. Br J Cancer 94: 1874-1878, 2006.

37. Ullrich A: Molecular targets in cancer therapy and their impact on cancer management. Oncology 63 (Suppl. 1): S1-S5, 2002.

38. Palmu S, Soderstrom KO, Quazi K, Isola J and Salminen E: Expression of C-KIT and HER-2 tyrosine kinase receptors in poor-prognosis breast cancer. Anticancer Res 22: 411-414, 2002 .

39. Yared MA, Middleton LP, Meric F, Cristofanilli M and Sahin AA: Expression of c-kit proto-oncogene product in breast tissue. Breast J 10: 323-327, 2004

40. Laakso M, Loman N, Borg A and Isola J: Cytokeratin 5/14positive breast cancer: true basal phenotype confined to BRCA1 tumors. Mod Pathol 18: 1321-1328, 2005.

41. Kim MJ, Ro JY, Ahn SH, Kim HH, Kim SB and Gong G: Clinicopathologic significance of the basal-like subtype of breast cancer: a comparison with hormone receptor and Her2/ neu-overexpressing phenotypes. Hum Pathol 37: 1217-1226, 2006. 